\title{
Subdural Hemorrhage Related to Birth
}

National Cancer Institute

\section{Source}

National Cancer Institute. Subdural Hemorrhage Related to Birth. NCI Thesaurus. Code C117306.

Bleeding within the subdural space occurring during labor and/or delivery. 